\title{
BRAZILIAN CONSENSUS STATEMENT ON VISCOSUPPLEMENTATION OF THE KNEE (COBRAVI)
}

\section{CONSENSO BRASILEIRO DE VISCOSSUPLEMENTAÇÃO DO JOELHO (COBRAVI)}

\author{
Gustavo Constantino de Campos ${ }^{1}$, Eduardo Branco de Sousa ${ }^{2}$, Paulo César Hamdan ${ }^{3}$, Cyro Scala de almeida Júnior ${ }^{4}$,

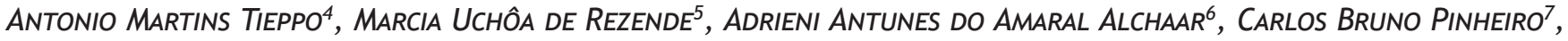 \\ Eduardo de Melo Carvalho Rocha ${ }^{4}$, Fabiano Gonçalves Cunha ${ }^{8}$, IVAN Pacheco ${ }^{9}$, Mário SÉrgio Rossi Vieira ${ }^{4}$, \\ SílVIo FigueIRa ANTONIO ${ }^{10}$, Zartur José BarCelos MENEGASSI ${ }^{3}$
}

1. Universidade Estadual de Campinas (UNICAMP), Campinas, SP, Brazil.

2. Instituto de Nacional da Traumatologia e Ortopedia (INTO), Rio de Janeiro, RJ, Brazil.

3. Universidade Federal do Rio de Janeiro (UFRJ), Rio de Janeiro, RJ, Brazil.

4. Santa Casa de São Paulo, Faculty of Medicine, São Paulo, SP, Brazil

5. Universidade de São Paulo, Faculdade de Medicina, Hospital das Clínicas, Department of Orthopedics and Traumatology (DOT/FMUSP), São Paulo, Brazil.

6. Hospital Municipal Miguel Couto, Rio de Janeiro, RJ, Brazil.

7. Hospital Evangélico do Rio de Janeiro, Rio de Janeiro, RJ, Brazil.

8. Hospital Santa Paula, São Paulo, SP, Brazil

9. Hospital Moinhos de Vento, Porto Alegre, RS, Brazil.

10. Hospital Estadual do Servidor Público, São Paulo, SP, Brazil.

\section{ABSTRACT}

Objective: The aim of this consensus statement on viscosupplementation is to serve as a reference document based on relevant literature and clinical experience in the treatment of knee osteoarthritis using an intra-articular injection of hyaluronic acid, covering key aspects such as clinical indications, effectiveness, and tolerability. Methods: A multidisciplinary panel including two sports medicine physicians, six orthopedists, four physiatrists, and two rheumatologists were selected based on their clinical and academic experience of viscosupplementation. Sixteen statements were prepared and discussed, after which a vote was held. Each member of the panel gave a score between 0 and 10 on a Likert scale, specifying their level of agreement with the statement. Results: The panel reached a consensus on several issues. Specifically, the panel agreed that the best indication is for mild to moderate knee arthrosis; prior or concomitant use of intraarticular triamcinolone hexacetonide may optimize the effect of hyaluronic acid; viscosupplementation should not be performed as an isolated procedure but in conjunction with other rehabilitative and pharmacological measures; viscosupplementation has analgesic, anti-inflammatory, and chondroprotective effects; and viscosupplementation is cost-effective. Conclusion: This consensus statement provides clear information and guidance for both individuals and payers. Level of evidence $V$, Consensus statement.

Keywords: Osteoarthritis. Knee. Viscosupplementation.

\section{RESUMO}

Objetivo: O Consenso Brasileiro de Viscossuplementação visa gerar uma fonte referencial e consensual, a partir de levantamentos bibliográficos relevantes, do conhecimento teórico e da experiência clínica de especialistas de áreas afins para tratamento de viscossuplementação na osteoartrite do joelho, mitigando pontos críticos desse procedimento, como via de aplicação, indicação, eficácia e tolerabilidade. Métodos: Um painel multidisciplinar foi formado com dois médicos do esporte, seis ortopedistas, quatro fisiatras e dois reumatologistas, com base nas experiências clínica e acadêmica no uso da viscossuplementação. Foram elaboradas, discutidas e votadas 16 afirmativas. Cada membro do painel deu um valor entre zero e 10, em uma escala tipo Likert, especificando seu nível de concordância com a afirmação. Resultados: O painel chegou a um consenso sobre diversos aspectos da viscossuplementação, com destaque para as seguintes afirmativas: a melhor indicação é para artrose de joelhos leve a moderada; o uso prévio ou concomitante de hexacetonido de triancinolona intra-articular pode otimizar o efeito do ácido hialurônico; a viscossuplementação não deve ser realizada como procedimento isolado no tratamento da OA, mas em conjunto com outras medidas reabilitadoras e farmacológicas; promove efeito analgésico; anti-inflamatório; condroprotetor; e é custo-efetiva. Conclusão: Este consenso traz informações claras e servirá, como guia tanto para médicos quanto para as fontes pagadoras. Nível de evidência $V$, Consenso de especialistas.

Descritores: Osteoartrite. Joelho. Viscossuplementação.

Citation: Campos GC, Sousa EB, Hamdan PC, Almeida Jr CS, Tieppo AM, Rezende MU, Alchaar AAA, Pinheiro CB, Rocha EMC, Cunha FG, Pacheco I, Vieira MSR, Antonio SF, Menegassi ZJB. Brazilian consensus statement on viscosupplementation of the knee (COBRAVI). Acta Ortop Bras. [online]. 2019;27(4):230-6. Available from URL: http://www.scielo.br/aob.

All authors declare no potential conflict of interest related to this article.

This study was conducted at Universidade Estadual de Campinas (UNICAMP), Campinas, SP, Brazil.

Correspondence: Marcia Uchoa de Rezende. Rua Dr. Ovidio Pires de Campos, 333, Cerqueira Cesar, São Paulo, SP, Brazil. 05403-010. murmedicina@gmail.com 


\section{INTRODUCTION}

Osteoarthritis $(\mathrm{OA})$ is the most prevalent joint disease and is associated with pain and disability. It is predicted that $25 \%$ of the adult population (more than 50 million people in the US) will be affected by this disease by 2020 and that OA will be a major cause of morbidity and restricted mobility in individuals over 40 years of age., ${ }^{1,2}$ The latest update of the 2013 Global Burden of Disease estimates that 242 million people worldwide live with symptoms and limitations due to osteoarthritis of the knees or hips. ${ }^{3}$

Viscosupplementation (VS) is the intra-articular injection of exogenous hyaluronic acid for the treatment of osteoarthritis. ${ }^{4}$ Hyaluronic acid exists in several organisms, and when it is not bound to other molecules, it binds to water and becomes gelatinous. It was first isolated in 1934 by Karl Meyer. ${ }^{5}$ Balazs popularised the name hyaluronan by using it to encompass the various forms that the molecule can take: the acid form, such as hyaluronic acid, and the salt form, such as sodium hyaluronate; Balazs is considered the pioneer in the use of this substance for the treatment of osteoarthritis. ${ }^{6}$ Intra-articular injection of hyaluronic acid has basically three main objectives: viscosupplementation itself, i.e., improving the rheological properties of the synovial fluid, serving both as a lubricant and as a shock absorber; analgesia; and improvement of joint homeostasis by decreasing inflammation and positively stimulating chondrocytes. ${ }^{4}$

The clinical outcomes of VS show a benefit with regard to pain relief, which has been demonstrated in several clinical trials and meta-analyses..$^{7-12}$ It is also considered a disease-modifying drug ${ }^{13,14}$ with benefits that have been observed over a period of 6 months to 2 years. ${ }^{15}$ It is believed that the long-term efficacy of hyaluronic acid is attributable to its modulatory action in the inflammatory process that occurs in the osteoarthritic joint and in its interaction with the receptors of CD44 synoviocytes. ${ }^{16,17}$ However, despite this robust evidence, the recent international guidelines are not unanimous regarding recommendations for its use. ${ }^{18-21}$

Thus, a multidisciplinary group was formed to generate a consensus reference document based on a review of relevant literature, theoretical knowledge and the clinical experience of specialists in areas related to viscosupplementation for knee osteoarthritis. We aimed to address critical aspects of this procedure such as injection approach, clinical indications, efficacy and tolerability. The statement is also intended to guide and support medical students, medical residents and managers of public and private health systems who seek to increase the use of this procedure and improve their medical practice to enhance the quality of life of individuals with osteoarthritis of the knees.

\section{MATERIALS AND METHODS}

A multidisciplinary panel including physicians in different specialties was formed. Participants were selected based on their clinical and academic experience in the use of viscosupplementation for the treatment of osteoarthritis. Two sports medicine physicians, 6 orthopaedists, 4 physiatrists) and 2 rheumatologists participated in the panel. Initial face-to-face meetings were held between 4 members to define the 16 statements to be discussed. Ethics approval was waived since it is an expert opinion paper.

Once the statements were defined, 1 panellist conducted a review of the relevant literature and distributed the selected articles to all panel members so that discussion and scores were based not only on personal experience but also on quality scientific evidence. The terms "viscosupplementation", "hyaluronic acid", "hylan", and "hyaluronan", in conjunction with the terms "osteoarthritis" and "knee" were used for the bibliographic search. Only articles in the English language were considered. The search was performed in the PubMed database and the articles considered most relevant were selected and distributed to all panel members. After reading the articles, all members of the panel convened for a meeting during which the statements were presented. All the statements were strongly debated before the vote. The vote was held after exhaustive debate of all questions raised regarding viscosupplementation.

Sixteen statements were prepared, discussed and voted on. For each of the statements, each panel member gave a score between 0 and 10 on a Likert scale, indicating their level of agreement with the statement. On this scale, the value zero meant "I completely disagree", and the value 10 meant "I completely agree". After the vote, the scores were grouped into 3 categories. Scores between 0 and 3 were classified as indicating "disagreement", scores between 4 and 6 were classified as indicating "indifference", and scores between 7 and 10 were classified as indicating "agreement". Finally, the level of agreement among panellists for each statement was summarised as "unanimously in favour" when all votes were greater than or equal to seven, "strongly in favour" when only one of the votes was not greater than or equal to seven, "moderately in favour" when only two to four votes were not greater than or equal to seven, "without consensus" when there was no category with at least four votes more than another category, "moderately against" when only two to four votes were greater than 3, "strongly against" when only one of the votes was greater than 3, and "unanimously against" when all votes were less than or equal to 3.

\section{RESULTS}

Statement 1. The best indication is for mild to moderate OA of the knee.

Agreement: 100\% - unanimously in favour

Mean: 9.78 Median: 10 Score range: 8-10

The panel was unanimously in favour of the statement, as was the American group for the Appropriate Use Criteria (AUC) of hyaluronic acid for OA of the knee, which in 2017 published an article stating that there is evidence in the literature to support that viscosupplementation is an appropriate treatment for patients with mild and moderate OA. ${ }^{22}$ Such a statement had previously been made by a consensus panel of European experts. ${ }^{23} \mathrm{~A}$ French study focusing on evidence from "real" studies has suggested that joint infiltration with hyaluronic acid appears to be more effective when the patient has mild to moderate OA. ${ }^{24}$ Viscosupplementationwas also recommended for patients with chronic, low-grade OA in the anterior, medial and lateral knee compartments. ${ }^{25}$

Statement 2. Viscosupplementation can be used as the first line of treatment.

Agreement: 92.86\% - strongly in favour

Mean: 8.85 Median: 9.5 Score range: 6-10

The AMELIA study showed that repeated cycles of intra-articular hyaluronic acid infiltration improves knee OA symptoms not only during the period between treatments but also for as long as one year after the last injection. ${ }^{15}$ Similarly, a Cochrane review conducted in 2006 and revisited in 2014 found that viscosupplementation is an effective treatment for OA of the knee, with beneficial effects on pain, function and overall assessment of the patient and over various post-treatment periods, especially between 5 and 13 weeks. ${ }^{9,26}$ A systematic review and meta-analysis confirmed that viscosupplementation is effective within 26 weeks after infiltration in patients with $\mathrm{OA}{ }^{27}$ Another meta-analysis found that there is good evidence in the literature on the efficacy of viscosupplementation in reducing pain and improving function in OA of the knee. ${ }^{7}$ Finally, the American group for the Appropriate Use Criteria of viscosupplementation for OA of the knee has recognised that there is a need to consider injections of hyaluronic acid as primary therapy 
given the expected increase in the prevalence of OA of the knee among American adults. ${ }^{22}$

Statement 3. Viscosupplementation may be indicated in cases of severe OA of the knee

Agreement: $85.71 \%$ - moderately in favour

Mean: 8.85 Median: 10 Score range: 5-10

Viscosupplementation improves pain and function in patients with OA of the knee. ${ }^{26}$ Guidelines on the clinical treatment of osteoarthritis suggest that viscosupplementation is indicated for the treatment of OA of the knee either alone ${ }^{18}$ or in combination with medications for symptomatic relief, ${ }^{20}$ mainly in patients with mild to moderate OA (classified as Kellgren \& Lawrence grades 2 and 3). However, several studies also suggest that viscosupplementation is beneficial in patients with severe $\mathrm{OA}$ of the knee. A recent randomised clinical trial demonstrated improvement of pain and function in patients with severe OA of the knee. ${ }^{28}$ Waddel et al. ${ }^{29}$ found that total knee arthroplasty was delayed by more than 7 years in $75 \%$ of 1863 knees with grade IV osteoarthritis (1342 patients) who had used viscosupplementation. The European Consensus ${ }^{23}$ also states that viscosupplementation may be beneficial in cases of severe osteoarthritis of the knees.

Statement 4. The prior or concomitant use of intra-articular triamcinolone hexacetonide may optimise the effect of hyaluronic acid. Agreement: $100 \%$ - unanimously in favour

Mean: 8.85 Median: 9.5 Score range: 7-10

The use of intra-articular corticosteroid in osteoarthritic knees leads to an improvement in pain and function for 2 to 4 weeks, after which the effect wanes. 8,12,30,31 Infiltration with hyaluronic acid also promotes antalgic effects and functional improvement, but with a later onset and longer duration (approximately 6 months). ${ }^{7,9}$ Based on these findings, in 2009 Bannuru et al. ${ }^{8}$ suggested that both medications should be used concurrently to achieve early and lasting pain control and functional improvement. This combination was studied by de Campos et al. in $2013^{12}$ In this study, the addition of $1 \mathrm{ml}$ of triamcinolone hexacetonide improved pain and function in the first week after viscosupplementation, without altering the incidence of adverse effects or even the long-term beneficial effect of viscosupplementation. This finding provides support for the effectiveness of combined corticosteroid and hyaluronic acid treatment in achieving early and lasting improvement of pain and function. Although studies on the combination of corticosteroids and hyaluronic acid consider only concomitant injection, the panel also considers it appropriate to perform the corticosteroid injection one week before the injection of the hyaluronic acid.

Statement 5 . The results of VS vary according to the viscosupplementation product used.

Agreement: $85.71 \%$ - moderately in favour

Mean: 8.21 Median: 8 Score range: 6-10

The products currently on the market differ in their origin (animal or biofermented), production method, molecular weight, rheological properties, presence of crosslinks, pharmacodynamics and duration of persistence in the joint. ${ }^{4}$ Some are still combined with anti-oxidants such as sorbitol or mannitol. ${ }^{32}$ In the panel's view, these variations play an important role in the discrepant and unclear recommendations currently found in some systematic reviews, meta-analyses, and guidelines that attempt to aggregate evidence on viscosupplementation by considering all viscosupplements as a single class of drugs. A review in the Journal of Bone and Joint Surgery (JBJS) that carefully examined more recently published studies suggests that viscosupplementation is a safe option with a clinically important reduction of pain in patients with OA of the knee, especially when using formulations with higher molecular weights or cross-links. ${ }^{33}$ The use of anti-oxidant substances may also potentiate the effects of viscosupplementation by reducing the rate of degradation of hyaluronic acid without increasing the risk of adverse events. ${ }^{32}$ Similar to the European Consensus panel, ${ }^{23}$ this panel finds that it is impossible to consider the different products as a single class. Thus, one cannot extrapolate the results from one product to another, nor perform meta-analyses by grouping results from different types of viscosupplements.

Statement 6 . The best access route for non-guided infiltration is the superolateral approach.

Agreement: 21.43\% - no consensus

Mean: 4.5 Median: 5 Score range: 0-9

There are several non-guided techniques for knee viscosupplementation described in the literature. Most studies show that insertion points lateral to the patella are more accurate when compared to the insertion points medial to the patella. ${ }^{34-36}$ The most cited approach in patients with associated joint effusion are the superolateral and the medial lateral patellar approaches, ${ }^{34,36}$ which are more accurate than medial approaches. When using the superolateral and direct lateral approaches, the patient should be placed in a supine position with the knee half-extended or fully extended. For the anterolateral approach, which is similar to that used for knee arthroscopy, the patient may be in a sitting position with the knee at 90 degrees, which some professionals prefer. Although the literature favours the superolateral approach, there was no consensus among panel members in this regard. As most studies have been conducted with patients with some degree of joint effusion, the panel's opinion is that individual clinical experience should be taken into account during the procedure, especially in patients without joint effusion.

Statement 7. Viscosupplementation should not be performed as the only procedure in the treatment of OA but together with other rehabilitative and pharmacological measures.

Agreement: $100 \%$ - unanimously in favour

Mean: 9.78 Median: 10 Score range: 7-10

The consensus statement of the European Society for Clinical and Economic Aspects of Osteoporosis and Osteoarthritis (ESCEO) ${ }^{20}$ published in 2014 stated that patients with mild to moderate OA of the knee can be appropriately managed with a set of core measures (education, diet and exercise) combined with the use of oral analgesics (Paracetamol), slow-acting symptomatic treatment (glucosamine and chondroitin) and topical anti-inflammatories. If necessary, advanced pharmacological measures, including non-selective and selective oral anti-inflammatory drugs, intra-articular corticosteroids and hyaluronic acid, may be added. This is consistent with virtually all guidelines and opinion articles on OA treatment, which recommend a multimodal approach to OA treatment with a central core of education, weight loss and physical activity, which can be complemented with other pharmacological therapies such as, for example, viscosupplementation.

Statement 8 . The number of treatments will depend on the patient's profile and the viscosupplements used.

Agreement: 92.86\% - strongly in favour

Mean: 8.71 Median: 9.5 Score range: 4-10

As discussed in the Statement 5 , there are various products currently on the market that differ from one another with regard to several characteristics. Some of these characteristics interfere with the longevity of viscosupplements in the joint. ${ }^{37,38}$ Because it remains in the joint for approximately 7 days, the classic regimen for sodium hyaluronate involves weekly injections with a total of 3 to 5 treatments, which allows a total time of action in the joint of 21 to 35 days. The literature demonstrates that the presence of cross-links greatly increases the longevity of the product in the joint, probably because 
it hinders resorption. ${ }^{37,38}$ Combination with anti-oxidant substances may also delay resorption of the product. ${ }^{32}$ The use of products with longer persistence allows for a treatment regimen with fewer injections, or even a single injection. Single-dose use was validated for high-molecular weight and cross-linked hylan in a controlled non-inferiority clinical trial. ${ }^{11}$ However, a prospective randomised study comparing two regimens with a linear sodium hyaluronate product of intermediate molecular weight (single injection of $6 \mathrm{ml}$ versus 3 weekly injections of $2 \mathrm{ml}$ ) demonstrated that the one-time injection did not provide the same efficacy. ${ }^{39}$

Statement 9. In cases of mild knee osteoarthritis, VS has a chondroprotective effect.

Agreement: $100 \%$ - unanimously in favour

Mean: 9 Median: 9 Score range: 7-10

A recent systematic review ${ }^{40}$ found 67 articles in the literature describing chondroprotective effects conferred by intra-articular injection of hyaluronic acid. Hyaluronic acid has several beneficial effects, including reduction of chondrocyte apoptosis and increased chondrocyte proliferation, ${ }^{41,42}$ and most of these effects are due to interaction with CD44 cell receptors. Binding to CD44 has a greater effect with viscosupplements of higher molecular weights. ${ }^{43}$ Studies by Bagga et al. in $2006^{44}$ and Band et al. in $2015^{45}$ examined the synovial fluid of patients with osteoarthritis of the knee who had received hyaluronic acid injections; improvements of pain and function were observed, probably due to the chondroprotective effect of the increased hyaluronic acid concentration in the synovial fluid. Studies with more objective findings have also published. Biopsies performed before and after VS showed reconstitution of the superficial layer, better quality of the matrix and higher density of chondrocytes, with a greater number of intracellular organelles after 6 months. ${ }^{13}$ "Second look" arthroscopies performed 1 year after starting treatment with hyaluronic acid found a better visual appearance of the articular surface compared to the placebo group. ${ }^{46}$ Finally, Jubb et al.$^{47}$ found that treatment with hyaluronic acid significantly reduced the progression of joint space loss in patients with milder degrees of $\mathrm{OA}$ of the knees compared to placebo.

Statement 10. VS may be indicated in patellofemoralchondropathy. Agreement: 85.71\% - moderately in favour

Mean: 8.21 Median: 8 Score range: 6-10

There are no prospective and randomised clinical trials on viscosupplementation aimed at treating patients with chondropathy and/or patellofemoral osteoarthritis of the knee, a condition often associated with anterior knee pain, which is often disabling. An open pilot study used hylan in patients with anterior knee pain due to patellofemoral arthrosis and demonstrated a reduction of pain (particularly when climbing stairs) and overall improvement in the condition of the participating patients according to validated measures. ${ }^{48}$ The decrease in pain was significant from week 4 and maintained until week 52.

A recent study reported improvement of pain in professional soccer players who received VS for the treatment of patellofemoral chondropathy. ${ }^{49}$ Frosted and Dagher ${ }^{50}$ were successful in the treatment of 25 patients with patellofemoral pain using an arthroscopic lateral release combined with viscosupplementation. Most participants in his panel recognise the potential beneficial effect of viscosupplementation in cases of patellofemoral pathology, especially when combined with non-pharmacological treatment for muscle strengthening.

Statement 11. Imaging guidance (by ultrasound, fluoroscopy, CT or other methods) is necessary to perform VS.

Agreement: $78.57 \%$ - moderately against

Mean: 2.28 Median: 2 Score range: 0-4
Hyaluronic acid $(\mathrm{HA})$ may be injected in different anatomical sites, with or without imaging guidance. ${ }^{34,51}$ However, to achieve their therapeutic benefit, hyaluronic acid derivatives should be injected directly into the space of the knee joint and not into the anterior adipose cushion or subsynovial tissues. ${ }^{4}$ In the absence of a knee effusion, reproducible placement of the needle into the intra-articular space can be a challenge. ${ }^{52}$ Anatomically guided injections, which rely on conventional palpation, often result in inaccurate needle positioning in the extra-articular tissue and adjacent structures. However, injections have traditionally been carried out this way and it is important to question whether the use of imaging can significantly improve the accuracy of injections. Bookman et al. ${ }^{51}$ report an accuracy of $92.7 \%$ using ultrasound-guided infiltration of the knee joint and $77.9 \%$ using blind methods; similar results were reported by Berkooff et al..53 95.8\% versus $77.8 \%$, respectively. A comparison between the effect of ultrasound-guided HA injection and blind $\mathrm{HA}$ injection in patients with $\mathrm{OA}$ of the knee was performed using clinical scores. Kianmehr et al. ${ }^{52}$ observed better WOMAC scores in patients who underwent guided injection than in those who underwent blind injection after 6 and 12 weeks. Even so, most doctors choose to perform blind knee infiltration. The panel of experts was moderately against the need for guided puncture in viscosupplementation. Blind injections at the superolateral patellar site have good accuracy, especially if performed by an experienced professional. ${ }^{54}$ The precision of needle placement varies from $63 \%$ to $100 \%$ with ultrasound and from $39 \%$ to $100 \%$ with conventional anatomical guidance. ${ }^{53}$

Statement 12. Viscosupplementation generates cost reductions for the supplementary health system, making it a cost-effective procedure.

Agreement: 92.86\% - strongly in favour

Mean: 8.85 Median: 9.5 Score range: 5-10

Osteoarthritis of the knee is a great burden to society because it is extremely prevalent, it severely decreases the quality of life of the affected individuals and it generates enormous costs. ${ }^{1,2,55}$ Thus, in addition to being effective, it is essential that any treatment for osteoarthritis be cost-effective. Several studies have studied the cost-effectiveness of viscosupplementation. A French multicentre study compared the costs and effectiveness of OA treatment with NSAIDs or hyaluronic acid and concluded that intra-articular (IA) HA treatment did not generate additional costs for the national health insurance system and was associated with functional improvement and better quality of life in patients with osteoarthritis of the knee. The cost-effectiveness analysis was in favour of VS. ${ }^{56}$ Another study conducted in individuals of productive age (between 18 and 65 years old) concluded that the addition of high-molecular weight hyaluronic acid to the routine OA treatment is cost-effective. ${ }^{57}$ Finally, a study carried out with the top 5 brands of hyaluronic acid on the American market concluded that viscosupplementation with any of was more cost-effective compared to routine treatment. Thus, the panel was strongly in agreement that viscosupplementation generates cost reductions for the supplementary health system and is a cost-effective procedure. ${ }^{58}$

Statement 13. Viscosupplementation has analgesic effects. Agreement: $100 \%$ - unanimously in favour Mean: 9.21 Median: 10 Score range: 7-10

VS promoted reduction of knee pain in all studies, based on both the WOMAC score and the visual analogue scale. The magnitude and duration of this pain reduction depended on the treatment used (corticosteroids, NSAIDs, placebo). The analgesic effect seems to be associated with the concentration of HA. ${ }^{59}$ In comparison to corticosteroids, VS led to a greater reduction of pain after the 5th week, mainly between the 5th and 13th weeks, and persisted until 
the 26th week. ${ }^{8}$ It has also recently been established that VS can relieve pain beyond 12 weeks, with effects lasting up to 40 months, whereas corticosteroid use is associated with pain reduction only in the first few weeks after infiltration. ${ }^{24}$

In comparing VS and placebo, the evidence shows that VS can reduce knee pain starting at around the 4th week and with a peak effect at the 8th week after HA infiltration. ${ }^{7,9}$ The effect may last up to 12 weeks, ${ }^{60}$ up to 26 weeks, ${ }^{27}$ or even for more than 26 weeks. ${ }^{11}$ Finally, not many differences were found between oral NSAIDs and VS. However, VS is preferred because it does not entail the adverse effects of NSAIDs, ${ }^{24,61}$ especially in older and high-risk patients. ${ }^{20}$

Statement 14. Viscosupplementation has anti-inflammatory effects. Agreement: $100 \%$ - unanimously in favour

Mean: 8.92 Median: 9 Score range: 7-10

The anti-inflammatory effects described in the literature are observed in both preclinical and clinical studies. The main anti-inflammatory effect of hyaluronic acid is mediated by binding to CD44 receptors and consequent inhibition of IL1 beta, liposaccharides and metalloproteases. ${ }^{17,40,62}$ According to Yasuda, ${ }^{17}$ hyaluronic acid has an anti-inflammatory effect in cultured synovial cells of patients with rheumatoid arthritis. This effect is mediated by binding to CD44 on U937 macrophages causing secondary inhibition of PGE2, inhibition of PGE2-stimulating liposaccharides (LPS) with consequent inhibition of COX2, and down-regulation of the kappa beta nuclear factor. According to Altman, ${ }^{40}$ viscosupplement preparations inhibit interleukin 1 (IL-1), metalloproteases (MMPs) and TNF and are thus considered to have anti-inflammatory and chondral stimulation effects. Henrontin ${ }^{62}$ demonstrated in adults with osteoarthritis that viscosupplementation leads to a decrease in the degradation of type 2 collagen, which also supports the ability of VS to reduce the inflammatory processes associated with osteoarthritis.

Statement 15. Viscosupplementation only has biomechanical effects.

Agreement: $100 \%$ - unanimously against

Mean: 0.35 Median: 0 Score range: 0-2

The exact mechanism of action of VS is unknown. Three major effects have been proposed: mechanical effects mediated by improvement of the rheology of synovial fluid, thereby optimising mechanical properties such as viscosity and load distribution; ${ }^{7}$ analgesic effects through the direct inhibition of nociceptive stimuli; $; 9$ and biological effects such as stimulation of the endogenous synthesis of $\mathrm{HA},{ }^{44}$ decreased inflammatory activity, ${ }^{63}$ stimulation of the production of extracellular matrix and the proliferation of chondrocytes, ${ }^{43}$ among others. A previous expert consensus statement published in 2015 established that when administered in early stages, VS has a chondroprotective effect. ${ }^{23} \mathrm{~A}$ systematic review published in the same year addressed several effects of VS in the treatment of OA of the knee, including mechanical effects, chondroprotective effects, anti-inflammatory effects, analgesia and interaction with the synthesis of glycosaminoglycans and subchondral bone. ${ }^{40}$ Therefore, the panel was unanimous in agreeing that the effect of VS is not solely mechanical.

Statement 16. VS improves quality of life in patients with OA of the knee.

Agreement: 100\% - unanimously in favour

Mean: 9.57 Median: 10 Score range: 7-10

The panel of experts agreed unanimously that VS improves quality of life in patients with OA of the knee. The positive impact of HA on quality of life in patients with $\mathrm{OA}$ of the knee was demonstrated in several studies, which reported increased scores on quality of life questionnaires such as the SF-36 or AOKHQOL after 3 to 6 months of treatment. ${ }^{56,58,64-66}$ The use of $\mathrm{HA}$ is associated with decreased pain severity, and this reflects improvements in mobility and function. ${ }^{65}$ It has been shown that VS can increase quality-adjusted life-years in patients with symptomatic OA of the knee. ${ }^{58} \mathrm{~A}$ recent pharmaco-economic study showed that the use of intra-articular HA did not generate additional costs for the health system and was associated with functional improvement and better quality of life in patients with OA of the knee. ${ }^{56}$

\section{DISCUSSION}

Viscosupplementation with intra-articular injection of hyaluronic acid has been widely used as part of the therapeutic arsenal in the conservative treatment of osteoarthritis of the knees. The literature on viscosupplementation is robust, but extremely heterogeneous and conflicting. In the face of contradictory evidence and inconclusive guidelines, physicians need other sources of information to guide their decisions and offer the best possible treatment to their patients. In this context, a consensus considering the opinion of experts in the area, including physicians in different specialties, can be highly valuable. This article constitutes the first Brazilian consensus statement on viscosupplementation and was developed by a multidisciplinary panel of two sports medicine physicians, 6 orthopaedists, 4 physiatrists and two rheumatologists.

Although it is extensive, the literature on viscosupplementation includes many studies with excessive comparisons and small samples, which does not allow adequate statistical power to draw consistent conclusions. In addition, some articles have been criticised for the involvement of the pharmaceutical industry in the design, analysis or funding of the studies. However, a careful examination of the most recently published articles indicates that viscosupplementation is a safe option with clinically important reduction of pain in patients with osteoarthritis of the knee (especially younger patients and those with less severe disease), especially in those formulations with higher molecular weights. ${ }^{33}$

Our panel was strongly in favour of the use of viscosupplementation as first-line treatment in osteoarthritis of the knees. The ESCEO guidelines, ${ }^{20}$ which recommend injections of hyaluronic acid, reserve its use as a second line of treatment, referring to it as "advanced pharmacological management" indicated for patients with moderate to severe pain that do not respond to common analgesics and/or chondroprotectors. First-line use allows intervention at earlier stages of osteoarthritis, and also obviates the misconception that viscosupplementation should only be used when no other medication or procedure has been successful. The panel also agreed unanimously that viscosupplementation is best indicated for mild to moderate cases. Regarding advanced stages of knee osteoarthritis, although the use of VS as an alternative to a knee prosthesis is not an ideal indication, it can bring benefits to those patients who cannot or do not wish to undergo total knee arthroplasty surgery. ${ }^{23,28}$

This panel also reviewed the available literature on the various forms of action of hyaluronic acid injected into the knee. The panel unanimously agreed that the effect of viscosupplementation is not purely mechanical and that it does not simply function as an "oil change" as some physicians have said to their patients. The literature demonstrates potent biological effects, such as modulation of inflammatory activity, ${ }^{16,17,63}$ chondrocyte stimulation ${ }^{42,43}$ and direct analgesia with decreased nociceptive activity. ${ }^{59}$

Optimising the effect of hyaluronic acid requires that it is injected correctly into the joint space. The panel moderately disagreed that imaging guidance such as USG or fluoroscopy is needed for puncture of the knee joint. Although there is literature demonstrating increased efficacy with the use of a guidance method, ${ }^{51-53}$ specialists feel comfortable with correct intra-articular positioning of the needle using only anatomical parameters. There was no consensus, however, on 
the best anatomical site to perform the injection. The puncture can be performed lateral or superolateral to the patella with the patient in the supine position and the knee extended, or with an anterolateral approach with the knee at 90 degrees. The panel concluded that physicians should use the technique with which they are more accustomed and feel more confident performing.

The panel was also unanimously in favor of the prior or concomitant use of intra-articular triamcinolone hexacetonide to optimise the effect of hyaluronic acid. Antioxidants agents have been also used in combination with hyaluronic acid to decelerate degradation by the reactive oxygen species and improve its residence time into the joint. Sorbitol and mannitol which have intrinsic free radical scavenger properties have been the most studied antioxidants. The oxygen free radicals neutralization by mannitol and sorbitol can delay the degradation of $\mathrm{HA}$ and also provide faster analgesia without safety issues. ${ }^{32}$
Finally, in spite of the current reluctance of payers to cover the costs of viscosupplementation, the present panel strongly agreed that viscosupplementation generates cost reductions for the supplementary health system and is a cost-effective procedure. The literature has quality studies that demonstrate greater gain in function, increase in quality-adjusted life years, and lower use of deleterious drugs such as NSAIDs when treatment with hyaluronic acid is incorporated into routine treatment for osteoarthritis of the knee. ${ }^{56-58}$

\section{CONCLUSION}

This expert consensus statement provides important information on the most important aspects of viscosupplementation and may serve as a guide for both physicians and payers regarding the treatment of osteoarthritis of the knees with hyaluronic acid.

AUTHORS' CONTRIBUTIONS: Each author made significant individual contributions to this manuscript. GCC (0000-0001-7811-7354)* conceived the idea, conducted a literature search, reviewed the relevant literature, defined the statements, discussed and voted the statements, collaborated with the manuscript, reviewed and agreed to the final manuscript. EBS (0000-0001-8577-6403)* discussed and voted the statements, collaborated with the manuscript, reviewed and agreed to the final manuscript. PCH (0000-0002-3931-9321)* conceived the idea, defined the statements, discussed and voted the statements, collaborated with the manuscript, reviewed and agreed to the final manuscript. CSAJ (0000-0002-9935-9632)* conceived the idea, defined the statements, discussed and voted the statements, collaborated with the manuscript, reviewed and agreed to the final manuscript. AMT (0000-0001-5573-1773)* conceived the idea, defined the statements, discussed and voted the statements, collaborated with the manuscript, reviewed and agreed to the final manuscript. MUR (0000-0002-2020-9501)* discussed and voted the statements, collaborated with the manuscript, reviewed and agreed to the final manuscript. AAAA (0000-0002-6418-8538) discussed and voted the statements, collaborated with the manuscript, reviewed and agreed to the final manuscript. CBP (0000-00027694-4273)* discussed and voted the statements, collaborated with the manuscript, reviewed and agreed to the final manuscript. EMCR (0000-0003-2078$5450)^{*}$ discussed and voted the statements, collaborated with the manuscript, reviewed and agreed to the final manuscript. FGC (0000-0002-6692-5335)* discussed and voted the statements, collaborated with the manuscript, reviewed and agreed to the final manuscript. IP (0000-0002-3109-3866)* discussed and voted the statements, collaborated with the manuscript, reviewed and agreed to the final manuscript. MSRV (0000-0002-6312-5164)* discussed and voted the statements, collaborated with the manuscript, reviewed and agreed to the final manuscript. SFA (0000-0002-0412-8306)* discussed and voted the statements, collaborated with the manuscript, reviewed and agreed to the final manuscript. ZJ BM (0000-0002-6902-0136)* discussed and voted the statements, collaborated with the manuscript, reviewed and agreed to the final manuscript. * ORCID (Open Researcher and Contributor ID).

\section{REFERENCES}

1. Helmick CG, Felson DT, Lawrence RC, Gabriel S, Hirsch R, Kwoh CK, et al Estimates of the prevalence of arthritis and other rheumatic conditions in the United States. Part I. Arthritis Rheum. 2008;58(1):15-25.

2. Lawrence RC, Felson DT, Helmick CG, Arnold LM, Choi H, Deyo RA, et al. Estimates of the prevalence of arthritis and other rheumatic conditions in the United States. Part II. Arthritis Rheum. 2008;58(1):26-35

3. Global Burden of Disease Study 2013 Collaborators. Global, regional, and national incidence, prevalence, and years lived with disability for 301 acute and chronic diseases and injuries in 188 countries, 1990-2013: a systematic analysis for the Global Burden of Disease Study 2013. Lancet. 2015;386(9995):743-800.

4. Rezende MU, Campos GC. Viscosuplementation. Rev Bras Ortop. 2012;47(2):160-4.

5. Meyer K, Palmer JW. The polysaccharide of the vitreous humor. J Biol Chem. 1934;107(3):629-34.

6. Balazs EA, Watson D, Duff IF, Roseman S. Hyaluronic acid in synovial fluid. I. Molecular parameters of hyaluronic acid in normal and arthritis human fluids. Arthritis Rheum. 1967;10(4):357-76.

7. Bannuru RR, Natov NS, Dasi UR, Schmid CH, McAlindon TE. Therapeutic trajectory following intra-articular hyaluronic acid injection in knee osteoarthritis--meta-analysis. Osteoarthritis Cartilage. 2011;19(6):611-9.

8. Bannuru RR, Natov NS, Obadan IE, Price LL, Schmid CH, McAlindon TE. Therapeutic trajectory of hyaluronic acid versus corticosteroids in the treatment of knee osteoarthritis: a systematic review and meta-analysis. Arthritis Rheum. 2009;61(12):1704-11

9. Bellamy N, Campbell J, Robinson V, Gee T, Bourne R, Wells G. Viscosupplementation for the treatment of osteoarthritis of the knee. Cochrane Database Syst Rev. 2006;(2):CD005321.

10. Divine JG, Shaffer MD. Use of viscosupplementation for knee osteoarthritis: an update. Curr Sports Med Rep. 2011;10(5):279-84.

11. Chevalier X, Jerosch J, Goupille P, van Dijk N, Luyten FP, Scott DL, et al. Single, intra-articular treatment with $6 \mathrm{ml}$ hylan G-F 20 in patients with symptomatic primary osteoarthritis of the knee: a randomised, multicentre, double-blind, placebo controlled trial. Ann Rheum Dis. 2010; 69(1):113-9.

12. de Campos GC, Rezende MU, Pailo AF, Frucchi R, Camargo OP. Adding triamcinolone improves viscosupplementation: a randomized clinical trial. Clin Orthop Relat Res. 2013;471(2):613-20.
13. Guidolin DD, Ronchetti IP, Lini E, Guerra D, Frizziero L. Morphological analysis of articular cartilage biopsies from a randomized, clinical study comparing the effects of 500-730 kDa sodium hyaluronate (Hyalgan) and methylprednisolone acetate on primary osteoarthritis of the knee. Osteoarthritis Cartilage. 2001;9(4):371-81.

14. Wang Y, Hall S, Hanna F, Wluka AE, Grant G, Marks $P$, et al. Effects of Hylan G-F 20 supplementation on cartilage preservation detected by magnetic resonance imaging in osteoarthritis of the knee: a two-year single-blind clinical trial. BMC Musculoskelet Disord. 2011;12:195.

15. Navarro-Sarabia F, Coronel P, Collantes E, Navarro FJ, de la Serna AR, Naranjo A, et al. A 40-month multicentre, randomised placebo-controlled study to assess the efficacy and carry-over effect of repeated intra-articular injections of hyaluronic acid in knee osteoarthritis: the AMELIA project. Ann Rheum Dis. 2011;70(11):1957-62

16. Wang CT, Lin YT, Chiang BL, Lin YH, Hou SM. High molecular weight hyaluronic acid down-regulates the gene expression of osteoarthritis-associated cytokines and enzymes in fibroblast-like synoviocytes from patients with early osteoarthritis. Osteoarthritis Cartilage. 2006;14(12):1237-47.

17. Yasuda T. Hyaluronan inhibits prostaglandin E2 production via CD44 in U937 human macrophages. Tohoku J Exp Med. 2010;220(3):229-35.

18. McAlindon TE, Bannuru RR, Sullivan MC, Arden NK, Berenbaum F, Bierma-Zeinstra SM, et al. OARSI guidelines for the non-surgical management of knee osteoarthritis. Osteoarthritis Cartilage. 2014;22(3):363-88.

19. Hochberg MC, Altman RD, April KT, Benkhalti M, Guyatt G, McGowan J, et al. American College of Rheumatology 2012 recommendations for the use of nonpharmacologic and pharmacologic therapies in osteoarthritis of the hand hip, and knee. Arthritis Care Res (Hoboken). 2012;64(4):465-74.

20. Bruyere O, Cooper C, Pelletier JP, Branco J, Brandi ML, Guillemin F, et al. An algorithm recommendation for the management of knee osteoarthritis in Europe and internationally: a report from a task force of the European Society for Clinical and Economic Aspects of Osteoporosis and Osteoarthritis (ESCEO). Semin Arthritis Rheum. 2014;44(3):253-63.

21. Jevsevar DS, Brown GA, Jones DL, Matzkin EG, Manner PA, Mooar P, et al. The American Academy of Orthopaedic Surgeons evidence-based guideline on: treatment of osteoarthritis of the knee, 2nd edition. J Bone Joint Surg. 2013;95(20):1885-6. 
22. Bhadra AK, Altman R, Dasa V, Myrick K, Rosen J, Vad V, et al. Appropriate Use Criteria for Hyaluronic Acid in the Treatment of Knee Osteoarthritis in the United States. Cartilage. 2017;8(3):234-54.

23. Henrotin Y, Raman R, Richette P, Bard H, Jerosch J, Conrozier T, et al. Consensus statement on viscosupplementation with hyaluronic acid for the management of osteoarthritis. Semin Arthritis Rheum. 2015;45(2):140-9.

24. Maheu E, Rannou F, Reginster JY. Efficacy and safety of hyaluronic acid in the management of osteoarthritis: Evidence from real-life setting trials and surveys. Semin Arthritis Rheum. 2016;45(4 Suppl):S28-33.

25. Levy DM, Petersen KA, Scalley Vaught M, Christian DR, Cole BJ. Injections for Knee Osteoarthritis: Corticosteroids, Viscosupplementation, Platelet-Rich Plasma, and Autologous Stem Cells. Arthroscopy. 2018;34(5):1730-43.

26. Evaniew N, Simunovic N, Karlsson J. Cochrane in CORR(R): Viscosupplementation for the treatment of osteoarthritis of the knee. Clin Orthop Relat Res. 2014;472(7):2028-34.

27. Strand V, McIntyre LF, Beach WR, Miller LE, Block JE. Safety and efficacy of US-approved viscosupplements for knee osteoarthritis: a systematic review and meta-analysis of randomized, saline-controlled trials. J Pain Res. 2015;8:217-28.

28. Campos ALS, EAlbuquerque RSP, da Silva EB, Fayad SG, Acerbi LD, de Almeida $\mathrm{FN}$, et al. Viscosupplementation in patients with severe osteoarthritis of the knee: six month follow-up of a randomized, double-blind clinical trial. Int Orthop. 2017;41(11):2273-80.

29. Waddell DD, Joseph B. Delayed Total Knee Replacement with Hylan G-F 20. J Knee Surg. 2016;29(2):159-68.

30. He WW, Kuang MJ, Zhao J, Sun L, Lu B, Wang Y, et al. Efficacy and safety of intraarticular hyaluronic acid and corticosteroid for knee osteoarthritis: A meta-analysis. Int J Surg. 2017;39:95-103.

31. Bellamy N, Campbell J, Robinson V, Gee T, Bourne R, Wells G. Intraarticular corticosteroid for treatment of osteoarthritis of the knee. Cochrane Database Syst Rev. 2006(2):CD005328

32. Conrozier T. Is the addition of a polyol to hyaluronic acid a significant advance in the treatment of osteoarthritis? Curr Rheumatol Rev. 2018;14(3):226-30.

33. Johal H, Devji T, Schemitsch EH, Bhandari M. Viscosupplementation in Knee Osteoarthritis: Evidence Revisited. JBJS Rev. 2016;4(4):e11-111.

34. Telikicherla M, Kamath SU. Accuracy of Needle Placement into the Intra-Articula Space of the Knee in Osteoarthritis Patients for Viscosupplementation. J Clin Diagn Res. 2016;10(2):RC15-7.

35. Esenyel C, Demirhan M, Esenyel M, Sonmez M, Kahraman S, Senel B, et al. Comparison of four different intra-articular injection sites in the knee: a cadaver study. Knee surgery, sports traumatology. Arthroscopy. 2007;15(5):573-7.

36. Legre-Boyer V. Viscosupplementation: techniques, indications, results. Orthop Traumatol Surg Res. 2015;101(1 Suppl):S101-8.

37. Larsen NE, Dursema HD, Pollak CT, Skrabut EM. Clearance kinetics of a hylan-based viscosupplement after intra-articular and intravenous administration in animal models. J Biomed Mater Res B Appl Biomater. 2012;100(2):457-62.

38. Brown TJ, Laurent UB, Fraser JR. Turnover of hyaluronan in synovial joints: elimination of labelled hyaluronan from the knee joint of the rabbit. Exp Physiol. 1991;76(1):125-34

39. Zoboli AA, Rezende MU, Campos GC, Pasqualin T, Frucchi R, Camargo OP. Prospective randomized clinical trial: single and weekly viscosupplementation. Acta Ortop Bras. 2013;21(5):271-5.

40. Altman RD, Manjoo A, Fierlinger A, Niazi F, Nicholls M. The mechanism of action for hyaluronic acid treatment in the osteoarthritic knee: a systematic review. BMC Musculoskelet Disord. 2015;16:321.

41. Brun P, Panfilo S, Daga Gordini D, Cortivo R, Abatangelo G. The effect of hyaluronan on CD44-mediated survival of normal and hydroxyl radical-damaged chondrocytes. Osteoarthritis Cartilage. 2003;11(3):208-16.

42. Brun P, Zavan B, Vindigni V, Schiavinato A, Pozzuoli A, lacobellis C, et al. In vitro response of osteoarthritic chondrocytes and fibroblast-like synoviocytes to a 500-730 kDahyaluronan amide derivative. J Biomed Mater Res B Appl Biomater. 2012;100(8):2073-81.

43. Ehlers EM, Behrens P, Wunsch L, Kuhnel W, Russlies M. Effects of hyaluronic acid on the morphology and proliferation of human chondrocytes in primary cell culture. Ann Anat. 2001;183(1):13-7.

44. Bagga $H$, Burkhardt D, Sambrook $P$, March L. Longterm effects of intraarticular hyaluronan on synovial fluid in osteoarthritis of the knee. J Rheumatol. 2006;33(5):946-50

45. Band PA, Heeter J, Wisniewski HG, Liublinska V, Pattanayak CW, Karia RJ, et al. Hyaluronan molecular weight distribution is associated with the risk of knee osteoarthritis progression. Osteoarthritis Cartilage. 2015;23(1):70-6.
46. Listrat V, Ayral X, Patarnello F, Bonvarlet JP, Simonnet J, Amor B, et al. Arthroscopic evaluation of potential structure modifying activity of hyaluronan (Hyalgan) in osteoarthritis of the knee. Osteoarthritis Cartilage. 1997;5(3):153-60.

47. Jubb RW, Piva S, Beinat L, Dacre J, Gishen P. A one-year, randomised, placebo (saline) controlled clinical trial of 500-730 kDa sodium hyaluronate (Hyalgan) on the radiological change in osteoarthritis of the knee.Int $\mathrm{J}$ Clin Pract. 2003;57(6):467-74

48. Clarke S, Lock V, Duddy J, Sharif M, Newman JH, Kirwan JR. Intra-articular hylan G-F 20 (Synvisc) in the management of patellofemoral osteoarthritis of the knee (POAK). Knee. 2005;12(1):57-62.

49. Tamburrino P, Castellacci E. Intra-articular injections of HYADD4-G in male professional soccer players with traumatic or degenerative knee chondropathy. A pilot, prospective study. J Sports Med Phys Fitness. 2016;56(12):1534-9.

50. Fosco M, Dagher E. Proposal of a therapeutic protocol for selected patients with patellofemoral knee osteoarthritis: arthroscopic lateral retinacular release followed by viscosupplementation. Musculoskelet Surg. 2016;100(3):171-8.

51. Bookman JS, Pereira DS. Ultrasound guidance for intra-articular knee and shoulder injections: a review. Bull Hosp Jt Dis (2013). 2014;72(4):266-70.

52. Kianmehr N, Hasanzadeh A, Naderi F, Khajoei S, Haghighi A. A randomized blinded comparative study of clinical response to surface anatomy guided injection versus sonography guided injection of hyaloronic acid in patients with primary knee osteoarthritis. Int J Rheum Dis. 2018;21(1):134-9.

53. Berkoff DJ, Miller LE, Block JE. Clinical utility of ultrasound guidance for intra-articular knee injections: a review. Clin Interv Aging. 2012;7:89-95.

54. Maricar N, Parkes MJ, Callaghan MJ, Felson DT, O $\square$ Neill TW. Where and how to inject the knee--a systematic review. Semin Arthritis Rheum. 2013;43(2):195-203.

55. Hunter DJ, Schofield D, Callander E. The individual and socioeconomic impact of osteoarthritis. Nat Rev Rheumatol. 2014;10(7):437-41.

56. Thomas T, Amouroux F, Vincent P. Intra articular hyaluronic acid in the management of knee osteoarthritis: Pharmaco-economic study from the perspective of the national health insurance system. PLoS One. 2017:12(3):e0173683

57. Hermans J, Reijman M, Goossens LMA, Verburg H, Bierma-Zeinstra SMA, Koopmanschap MA. Cost-Utility Analysis of High Molecular Weight Hyaluronic Acid for Knee Osteoarthritis in Everyday Clinical Care in Patients at a Working Age: An Economic Evaluation of a Randomized Clinical Trial. Arthritis Care Res (Hoboken). 2018;70(1):89-97.

58. Rosen J, Sancheti P, Fierlinger A, Niazi F, Johal H, Bedi A. Cost-Effectiveness of Different Forms of Intra-Articular Injections for the Treatment of Osteoarthritis of the Knee. Adv Ther. 2016;33(6):998-1011.

59. Gomis A, Miralles A, Schmidt RF, Belmonte C. Intra-articular injections of hyaluronan solutions of different elastoviscosity reduce nociceptive nerve activity in a model of osteoarthritic knee joint of the guinea pig. Osteoarthritis Cartilage. 2009;17(6):798-804

60. Richette P, Chevalier X, Ea HK, Eymard F, Henrotin Y, Ornetti P, et al., Hyaluronan for knee osteoarthritis: an updated meta-analysis of trials with low risk of bias. RMD Open. 2015;1(1):e000071.

61. Campbell KA, Erickson BJ, Saltzman BM, Mascarenhas R, Bach Jr BR, Cole BJ, et al. Is Local Viscosupplementation Injection Clinically Superior to Other Therapies in the Treatment of Osteoarthritis of the Knee: A Systematic Review of Overlapping Meta-analyses. Arthroscopy. 2015;31(10):2036-45.e14.

62. Henrotin Y, Chevalier X, Deberg M, Balblanc JC, Richette P, Mulleman D, et al. Early decrease of serum biomarkers of type II collagen degradation (Coll2-1) and joint inflammation (Coll2-1 NO(2) ) by hyaluronic acid intra-articular injections in patients with knee osteoarthritis: a research study part of the Biovisco study. J Orthop Res. 2013;31(6): 901-7.

63. Piuzzi NS, Midura RJ, Muschler GF, Hascall VC. Intra-articular hyaluronan injections for the treatment of osteoarthritis: perspective for the mechanism of action. Ther Adv Musculoskelet Dis. 2018;10(2):55-7.

64. Khanasuk Y, Dechmaneenin T, Tanavalee A. Prospective randomized trial comparing the efficacy of single 6-ml injection of hylan G-F 20 and hyaluronic acid for primary knee arthritis: a preliminary study. J Med Assoc Thai. 2012;95(Suppl 10):S92-7.

65. Vincent HK, Montero C, Conrad BP, Horodyski M, Connelly J, Martenson M, et al. "Functional pain," functional outcomes, and quality of life after hyaluronic acid intra-articular injection for knee osteoarthritis. PM R. 2013;5(4):310-8.

66. Rat AC, Baumann C, Guillemin F. National, multicentre, prospective study of quality of life in patients with osteoarthritis of the knee treated with hylane G-F 20. Clin Rheumatol. 2011;30(10):1285-93. 